\title{
A IMPORTÂNCIA DA CURVA ABC NA ADMINISTRAÇÃO DE MATERIAIS: UM ESTUDO DE CASO EM UMA INSTITUIÇÃO DE ENSINO SUPERIOR EM PORTO VELHO - RONDÔNIA.
}

\author{
Robercy Moreira da Matta Neto ${ }^{1}$, Clara Caroline Felix da Silva ${ }^{2}$, Armando Araújo de Souza Júnior ${ }^{3}$
}

\begin{abstract}
RESUMO
Analisar a importância da Curva $\mathrm{ABC}$ na administração de materiais de uma Instituição de Nível Superior em Porto Velho - Rondônia. Para isso utilizou-se pesquisa de campo, que tem como finalidade aprofundar e fazer levantamentos das informações necessárias para que se chegue ao objetivo de compreender a funcionalidade do setor responsável pela administração de materiais, identificar os materiais mais rotativos dentro da instituição e finalizar com a aplicabilidade da curva $\mathrm{ABC}$ para uma análise holística de pontos negativos e positivos acerca dos materiais e capitais administrados dentro da instituição. A pesquisa apresentou para instituição a visibilidade de que o setor responsável pela administração de materiais dentro da empresa tem grande contribuição para tomadas de decisões, além de oferecer ao leitor o entendimento em relação ao controle administrativo de materiais e a contribuição de melhoria com a aplicabilidade da ferramenta curva $\mathrm{ABC}$ poderá contribuir nas ações futuras.
\end{abstract}

Palavras chave: Administração de materiais. Curva ABC. Controle de Estoque.

\begin{abstract}
This work had the objective of analyzing the importance of the ABC Curve in the administration of materials of a Higher Education Institution in Porto Velho - Rondônia. Field research was used to deepen and survey the information needed to arrive at the ultimate goal of understanding the functionality of the industry responsible for managing materials, identifying the most rotating materials within the institution, and finalizing with the applicability of the $\mathrm{ABC}$ curve for a holistic analysis of negative and positive points about materials and capital administered within the institution. The research presented to the institution the visibility that the sector responsible for the administration of materials within the company has a great contribution to decision making, besides offering the reader the understanding regarding the administrative control of materials and the contribution of improvement with the applicability of the tool curve $\mathrm{ABC}$ may contribute to future actions.
\end{abstract}

Keywords: Materials Management. ABC Curve. Inventory Control.

\section{INTRODUÇÃO}

A procura constante pela eficiência na administração das organizações sempre foi uma das maiores preocupações dos estudiosos e administradores na busca de melhoria contínua nas organizações. A tão desejada eficiência encontra-se baseada principalmente nas tarefas e

\footnotetext{
${ }^{1}$ Pós-Graduação - Mestrado em Engenharia da Produção pela Universidade Federal do Amazonas - UFAM robercy@gmail.com

${ }^{2}$ Faculdade de Rondônia - FARO.

${ }^{3}$ Universidade Federal do Amazonas - UFAM.
} 
na estrutura da administração de materiais que existe há muitos anos, desde a Revolução Industrial, período este que aumentou a concorrência de mercado e causou uma melhoria significativa na comercialização dos produtos, fazendo com que "compras" e "estoques" ganhassem maior importância.

Cabe ressaltar que desde a Revolução Industrial existe-se o lastro de significativas modificações na fabricação e estocagem em grande escala, mas tudo isso era feito artesanalmente, e aos poucos foi sendo substituído por máquinas, fazendo a produção evoluir para um estágio mais avançado, fazendo com que os estoques passassem a ser vistos com outros olhos se tornando um dos principais objetivos de uma organização.

Os estoques são investimentos que perfazem o capital da empresa e esta imobilizado em materiais e bens. Ademais, o capital encontra-se disponível para o uso alternativo.

As empresas precisam ter a sua disposição cinco tipos de recursos: materiais, patrimoniais, de capital ou financeiro, humano e tecnológico.

A administração de recursos patrimoniais trata da sequência de operações que, assim como a administração dos recursos materiais, tem inicio na identificação do fornecedor, passando pela compra e recebimento do bem, para depois lidar com sua conservação, manutenção ou, quando for o caso, alienação (MARTINS, 2005).

Tratando-se de patrimônio conceitua-se o mesmo como o conjunto de bens, valores, direitos e obrigações de uma pessoa física ou jurídica que possa ser avaliado pecuniariamente e que seja utilizado na consecução de seus objetivos sociais.

Administrar o patrimônio significa gerir os direitos e obrigações, ou, de outro modo, os ativos e passivos da empresa. Muitas vezes o passivo é maior que o ativo, gerando o que se denomina patrimônio liquido negativo (MARTINS, 2005).

Considerando o contexto da pesquisa, o setor responsável pela distribuição de materiais de expediente e manutenção obtém uma rotatividade nas solicitações de materiais muito elevada, com isso a falta de responsabilidade no gerenciamento ocasiona uma consequência que não favorece a produtividade positiva nos relatórios futuros do setor responsável, por exemplo, quando se realiza o inventário a diferença entre o estoque físico e o sistema surge com contradições de informações que consequentemente acaba fazendo com o que o trabalho do mesmo seja feito novamente e posto isto ocasionando-se um atraso no processo dentro do setor.

Diante dos fatos expostos a pesquisa procurou obter respostas para o seguinte problema: Qual a importância da curva $A B C$ na administração de materiais: Um estudo de caso em uma Instituição de nível superior em Porto Velho-RO? Baseando-se nas hipóteses de 
de que há uma necessidade de obter o conhecimento do processo e administração do setor responsável pelo controle de estoque, tendo como consequência a analise dos produtos mais rotativos da instituição e por fim coletando todas as informações necessárias para aplicar-se a ferramenta curva $\mathrm{ABC}$ e tendo oportunidade de obter uma visão holística do controle de estoque e dos materiais mais rotativos, assim tendo como objetivo a aplicação de novas estratégias e equilíbrio para um controle aprimorado, visando melhorar aquisição adequada de materiais, diminuição de imobilização de capital em estoque com a finalidade de administrar de forma positiva a instituição.

Sendo assim, a pesquisa justifica-se pela importância social para a Instituição por contribuir com a visibilidade e finalidade de que o setor responsável pela aquisição e distribuição de materiais e bens pode atuar como grande contribuinte para auxiliar nas tomadas de decisões da empresa, além de oferecer ao leitor a importância e o entendimento do controle administrativo com os materiais.

\section{ADMINISTRAÇÃO DA PRODUÇão}

Conforme, Chiavenato (2014), vivemos numa sociedade de organizações, quase tudo se não tudo é projetado, criado, produzido e distribuídos por organizações, à produção é o objetivo fundamental de toda e qualquer organização. Produção significa a transformação de insumos em produtos ou serviços, é um conjunto de atividades que permitem a conversão de um bem para outro, a produção necessita de recursos e competências para que os resultados gerados sejam possíveis.

Ainda seguindo o pensamento de Chiavenato, (2008) As empresas que tem o setor responsável por esses procedimentos, controles e distribuição de mercadorias ou serviços tem um modelo a aderi de produção, que são elas:

Empresas primárias ou extrativas: São aquelas que desenvolvem atividades, como agrícolas, pastoris, de pesca e entre outros. São chamadas primárias porque se dedicam basicamente à obtenção e extração de matérias primas, o elemento primário de toda a produção.

Empresas secundárias ou de transformação: São aquelas que processam as matérias-primas e transformam em produtos acabados. São as empresas produtoras de bens, isto é, de produtos tangíveis ou manufaturados.

Empresas terciárias ou prestadoras de serviços: São aquelas que executam e prestam serviços 
especializados. Nesses serviços estão inclusos os bancos, universidades e serviços de comunicação.

Um modelo de transformação é composto por "input”, processo de transformação e "output". Os inputs são os recursos de entrada geralmente classificados recursos a serem transformados e recursos de transformação. Os recursos a serem transformados são materiais, informações e consumidores. Os recursos de transformação são compostos por instalações, prédios, equipamentos, tecnologia e funcionários pessoas que operam as instalações (SLACK, 2018).

Por seguinte, tende-se de que o setor responsável pela elaboração de produtos ou serviços de uma determinada empresa tem suma importância no mercado, atualmente muitas empresas tem buscado interligar a administração de produção com a administração de materiais, pois ambos têm sua responsabilidade e credibilidade para o desenvolvimento, destaque e contribuição para tomadas de decisões de uma empresa no mercado.

Com a colaboração da tecnologia, podemos dizer que a evolução do processo de administração da produção tem feito com que a empresa em si valorize a agilidade e qualidade do processo de produção para que chegue ao consumidor final com qualidade no produto ou serviç̧o.

Para colaborar com o gerenciamento de qualidade, existe o PCP (Planejamento e controle da produção) que visa aumentar as atividades e a eficiência e eficácia da empresa através da administração da produção (SLACK, 2014).

Sendo assim, expostos alguns fatores que contribuem para o entendimento da importância do setor e profissional que exerce atividades na área de administração de produção dentro de uma empresa, pode-se compreender que essa área tem sob seus cuidados os recursos físicos e materiais de uma empresa, tendo como finalidades principais aumentar, aperfeiçoar, e garantir a produção, assim como garantir a qualidade final do produto fabricado.

\subsection{Administração de materiais}

A Administração de materiais não se relaciona exclusivamente com controle de estoques, há vários campos além de materiais e financeiros que precisam ser bem administrados para haver redução de custos e desperdício, para assim alavancar os resultados da empresa como um todo (VIANA, 2010). 
Há uma série de processamentos que dão inicio as operações, identificações e escolha de fornecedores, compra de um bem e recebimento do mesmo, transporte durante o processo produtivo e armazenagem e sua distribuição ao consumidor final.

De acordo com Viana (2010) o mesmo afirma que cada item citado há sua importância no processo interno e externo para que o setor/empresa tenha resultados positivos e o mínimo possível de problemas.

Contendo todos os processos e operações, a função da administração de materiais é reter a menor quantia de capital em estoque, o setor de compras é responsável por grandes tomadas de decisões que como consequência podem trazer benefícios ou malefícios para a empresa, trata-se de um local onde a rotatividade é maior do que outros departamentos, sendo assim o setor de compras tem um papel verdadeiramente estratégico nos negócios de uma empresa (MARTINS, 2005).

Expostos afirmações referente aos processos e a importância da administração de materiais para as empresas, pode-se afirmar que a administração de materiais é um equilíbrio para tomadas de decisões chaves, ligado diretamente ao setor de compras, que tem como finalidade ter o melhor processo de investimentos e planejamentos estratégicos para reduzir o máximo de problemáticas na empresa. Há muitos empresários que não tem a definição certa sobre ter a certeza de que o estoque é um recurso da empresa.

$\mathrm{Na}$ administração de materiais os itens têm suas classificações, dependendo do ramo que a empresa exerce sua atividade e o perfil de demanda atingida, cada empresa tem sua forma de classificação e identificação de materiais (BALLOU, 2013).

O sistema classificatório pode servir, dependendo da situação, de processo de seleção para identificar e decidir prioridades.

Existem infinitas formas de classificação, mas podem-se citar alguns principais que permitirá adaptações às necessidades de cada empresa (VIANA, 2010, p. 51):

- $\quad$ Abrangência deve tratar de uma gama de características em vez de reunir apenas materiais para serem classificados.

- Flexibilidade deve permitir interfaces entre os diversos tipos de classificação, de modo que se obtenha ampla visão do gerenciamento de estoques.

- $\quad$ Praticidade a classificação deve ser direta e simples.

Para atender às necessidades de cada empresa, é necessária uma divisão que norteie formas de classificação. Como existem vários tipos, a classificação deve ser analisada no todo, em conjunto, visando propiciar decisões e resultados que contribuam para atenuar o risco (VIANA, 2010). 
Seguidamente o autor menciona que há algumas características a afirmar também referente aos estoques, existem dois tipos de estocagem, o permanente e o temporário. $\mathrm{O}$ permanente é o material ou produto que tenham o maior giro de estoque, ou renovação automática de estoque, o temporário é o de materiais que tenha somente um período de armazenamento até a utilização total do mesmo.

Além de suas estratégias e métodos de classificação, o setor de compras conta com grandes ferramentas tecnológicas desenvolvidas para auxiliar nas execuções de atividades realizadas pelo setor.

É fundamental para o desenvolvimento das empresas o suporte da tecnologia, tratando-se do setor de compras, pode-se dizer que facilita no processo final das informações, cadastros dos produtos e procura do mesmo e um dos fatores mais importantes, a amostragem da quantidade de giros realizados em um determinado período e os investimentos realizados no mesmo.

De forma geral, a introdução de sistemas informatizados, qualquer que seja o setor alvo da empresa, tem finalidade, independente de se obterem as informações necessárias em tempo real, de modernizar procedimentos por meio da implementação da primazia pela qualidade, envolvendo a estrutura organizacional para assegurar a melhoria de serviços (VIANA, 2010).

Sendo assim, a administração de materiais pode ser definida como um conjunto de atividades que integram um circuito de compras, recebimento, armazenagem e produção, ou ainda uma gestão total do controle de estoques, garantindo a existência contínua do mesmo. Nos dias atuais, a administração de materiais é conceituada como uns sistemas integrados no qual diversos outros subsistemas interagem entre si, culminando em dois eventos majoritários, que são: tempo oportuno e quantidade ideal (ALBUQUERQUE, 2013).

\subsection{Estoque}

Estoque é como a acumulação armazenada de recursos materiais em um sistema de transformação. Algumas vezes o estoque também é usado para descrever qualquer recurso armazenado. Todavia apesar de esses recursos de transformação serem tecnicamente considerado como estoque, não são obtido sempre que um consumidor faz uma solicitação, eles não são o que normalmente se quer dizer com o termo estoque (SLACK, 2018). 
Sugestiona Martins (2006) que são classificados em: Compra de mercadoria, recebimento e inspeção do material, armazenagem, técnicas de separação de pedidos, transporte de mercadorias dentro do ambiente, entre outras.

De acordo com Ballou (2013), estoques são pilhas de matérias-primas, insumos, componentes, produtos em processo e produtos acabados que aparecem em numerosos pontos por todos os canais logísticos e de produção da empresa.

Os estoques são recursos ociosos que possuem valor econômico, os quais representam um investimento destinado a incrementar as atividades de produção e servir aos clientes (VIANA, 2010).

\subsection{Curva ABC}

Conforme Pozo (2016, p. 82) "o principio da Curva ABC foi elaborado, inicialmente, por Vilfredo Pareto, na Itália, no fim do século passado, quando por volta do ano de 1987 elaboraram um estudo de distribuição de renda e riqueza da população local”, para iniciar-se o foco para as concentrações nas populações.

Nesse estudo, Pareto notou que grande porcentagem da renda total se concentrava nas mãos de uma pequena parcela da população, numa proporção de aproximadamente $80 \%$ e $20 \%$ respectivamente, ou seja, que $80 \%$ da riqueza local estava concentrada com $20 \%$ da população. Esse principio geral, mais tarde, foi difundido para outras atividades e passou a ser uma ferramenta muito útil para os administradores.

Sendo assim, compreende-se que através da análise acima, podemos enfatizar como disse Martins (2005), a função da administração de materiais é reter a menor quantia de capital em estoque, o setor de compras é responsável por grandes tomadas de decisões que como consequência podem trazer benefícios ou malefícios para a empresa, trata-se de um local onde a rotatividade é maior do que outros departamentos, sendo assim o setor de compras tem um papel verdadeiramente estratégico nos negócios de uma empresa.

Nesse enfoque, na área administrativa, a Curva $\mathrm{ABC}$ tornou-se utilidade ampla nos mais diversos setores em que se necessita tomar decisões envolvendo grande volume de dados e a ação de estoques, produção, vendas, salários e outros. A curva $\mathrm{ABC}$ é um método que pode ser utilizado para qualquer atividade ou trabalho, porém, no controle de estoque.

Sua grande eficácia está na diferenciação dos itens de estoque, com vistas a seu controle e, principalmente, ao seu custo (POZO, 2016). 
Doravante, Martins (2005) afirma que a análise ABC é uma das formas mais usuais de se examinar estoques. Essa análise consiste na verificação, em certo espaço de tempo (normalmente 06 meses ou 1 ano), do consumo, em valor monetário ou quantidade, dos itens de estoque, para que eles possam ser classificados em ordem decrescente de importância. Aos itens mais importantes de todos, segundo a ótica do valor ou da quantidade, dá-se a denominação itens classe A, aos intermediários da classe B e aos menos importantes, itens classe C.

Seguindo Martins (2005, p. 165), a análise ABC de estoques, que multiplica os custos unitários com o volume comprado, permite que cada classe (A, B ou C) tenha um tratamento diferenciado. Os itens de classe A devem receber mais atenção, pois, uma economia ou melhoria sem sua utilização (por exemplo, de 10\%) representa uma economia (no caso, de $6 \%$ ) no total dos gastos com materiais.

O primeiro passo fazer para identificar os itens $\mathrm{ABC}$, é relacionar todos os itens de movimento em estoque, tais como, consumo e custo unitário.

Tabela $n^{\circ} 1$ - Apresentação de movimentação da empresa

\begin{tabular}{|c|c|c|}
\hline Item & $\begin{array}{c}\text { Consumo } \\
\text { Unidades/Ano) }\end{array}$ & Custo (R \$/Unidade) \\
\hline 1010 & 450 & $\mathrm{R} \$ 2,35$ \\
\hline 1020 & 23590 & $\mathrm{R} \$ 0,45$ \\
\hline 1030 & 12025 & $\mathrm{R} \$ 2,05$ \\
\hline 1045 & 670 & $\mathrm{R} \$ 3,60$ \\
\hline 1060 & 25 & $\mathrm{R} \$ 150,00$ \\
\hline 2015 & 6540 & $\mathrm{R} \$ 0,80$ \\
\hline 2035 & 2460 & $\mathrm{R} \$ 12,00$ \\
\hline 2050 & 3480 & $\mathrm{R} \$ 2,60$ \\
\hline 3010 & 1250 & $\mathrm{R} \$ 0,08$ \\
\hline 3025 & 4020 & $\mathrm{R} \$ 0,50$ \\
\hline 3055 & 1890 & $\mathrm{R} \$ 2,75$ \\
\hline 5050 & 680 & $\mathrm{R} \$ 3,90$ \\
\hline 5070 & 345 & $\mathrm{R} \$ 6,80$ \\
\hline 6070 & 9870 & $\mathrm{R} \$ 0,75$ \\
\hline 7080 & 5680 & $\mathrm{R} \$ 0,35$ \\
\hline
\end{tabular}

Fonte: Martins (2005, p. 162)

Após todos os dados de itens relacionados, multiplica se a quantidade consumida no período x, que é em média de 06 meses ou de 01 ano, pelo valor unitário. 
Tabela $\mathrm{n}^{\mathrm{o}} 2$ - Cálculo de valor monetário consumido

\begin{tabular}{|c|c|c|}
\hline Item & $\begin{array}{c}\text { Consumo } \\
\text { (Unidades/Ano) }\end{array}$ & $\begin{array}{c}\text { Custo } \\
\text { (R\$/Unidade) }\end{array}$ \\
\hline 1010 & $450 \times R \$ 2,35$ & $\mathrm{R} \$ 1.057,50$ \\
\hline 1020 & $23590 \times R \$ 0,45$ & $\mathrm{R} \$ 10.615,50$ \\
\hline 1030 & $12025 \times R \$ 2,05$ & $\mathrm{R} \$ 24.651,25$ \\
\hline 1045 & $670 \times R \$ 3,60$ & $\mathrm{R} \$ 2.412,00$ \\
\hline 1060 & $25 \times R \$ 150$ & $\mathrm{R} \$ 3.750,00$ \\
\hline 2015 & $6540 x R \$ 0,80$ & $\mathrm{R} \$ 100,00$ \\
\hline 2035 & $2460 x R \$ 12,00$ & $\mathrm{R} \$ 29.520,00$ \\
\hline 2050 & $3480 x R \$ 2,60$ & $\mathrm{R} \$ 9.048,00$ \\
\hline 3010 & $1250 \times R \$ 0,08$ & $\mathrm{R} \$ 100,00$ \\
\hline 3025 & $4020 \times R \$ 0,50$ & $\mathrm{R} \$ 2.010,00$ \\
\hline 3055 & $1890 \times R \$ 2,75$ & $\mathrm{R} \$ 5.197,50$ \\
\hline 5050 & $680 X R \$ 3,90$ & $\mathrm{R} \$ 2.652,00$ \\
\hline 5070 & $345 X R \$ 6,80$ & $\mathrm{R} \$ 2.346,00$ \\
\hline 6070 & $9870 \mathrm{XR} \$ 0,75$ & $\mathrm{R} \$ 7.402,50$ \\
\hline 7080 & $5680 \times R \$ 0,35$ & $\mathrm{R} \$ 1.988,00$ \\
\hline
\end{tabular}

Fonte: Martins (2005, P. 163)

Em seguida com os dados de valores unitários totais já elaborados, precisam-se ordenar todos os itens de forma decrescente de maior valor para menor valor unitário total.

Tabela $\mathrm{n}^{\circ} 3$ - Itens ordenados de forma decrescente

\begin{tabular}{|c|c|}
\hline Item & Valor consumido \\
\hline 2035 & $\mathrm{R} \$ 29.520,00$ \\
\hline 1030 & $\mathrm{R} \$ 24.651,25$ \\
\hline 1020 & $\mathrm{R} \$ 10.615,50$ \\
\hline 2050 & $\mathrm{R} \$ 9.048,00$ \\
\hline 6070 & $\mathrm{R} \$ 7.402,50$ \\
\hline 2015 & $\mathrm{R} \$ 5.232,00$ \\
\hline 3055 & $\mathrm{R} \$ 5.197,50$ \\
\hline 1060 & $\mathrm{R} \$ 3.750,00$ \\
\hline 5050 & $\mathrm{R} \$ 2.652,00$ \\
\hline 1045 & $\mathrm{R} \$ 2.412,00$ \\
\hline 5070 & $\mathrm{R} \$ 2.346,00$ \\
\hline 3025 & $\mathrm{R} \$ 2.010,00$ \\
\hline 7080 & $\mathrm{R} \$ 1.988,00$ \\
\hline 1010 & $\mathrm{R} \$ 1.057,50$ \\
\hline 3010 & $\mathrm{R} \$ 100,00$ \\
\hline Total & $\mathbf{R} \$ 10.7982,25$ \\
\hline
\end{tabular}

Fonte: Martins (2005, P.163)

Com o resultado total de consumo em valor de cada item, deve se tirar a porcentagem unitária e depois acumulada, assim terá uma visão do grau de importância e definir quais são os itens de classe A, B e C. 
Tabela $\mathrm{n}^{\circ} 4$ - Analise ABC

\begin{tabular}{|c|c|c|c|}
\hline Item & (Valor consumido/ValorTotal $) \times 100 \%$ & Percentual & Percentual Acumulado \\
\hline 2035 & $(\mathrm{R} \$ 29.520,00 / \mathrm{R} \$ 10.7982,25) \times 100 \%$ & $27,34 \%$ & $27,34 \%$ \\
\hline 1030 & $(\mathrm{R} \$ 24651,25 / \mathrm{R} \$ 10.7982,25) \times 100 \%$ & $22,83 \%$ & $50,17 \%$ \\
\hline 1020 & $(\mathrm{R} \$ 10615,50 / \mathrm{R} \$ 10.7982,25) \times 100 \%$ & $9,83 \%$ & $60,00 \%$ \\
\hline 2050 & $(\mathrm{R} \$ 9048,00 / \mathrm{R} \$ 10.7982,25) \times 100 \%$ & $8,38 \%$ & $68,38 \%$ \\
\hline 6070 & $(\mathrm{R} \$ 7402,50 / \mathrm{R} \$ 10.7982,25) \times 100 \%$ & $6,86 \%$ & $75,23 \%$ \\
\hline 2015 & $(\mathrm{R} \$ 5232,00 / \mathrm{R} \$ 10.7982,25) \times 100 \%$ & $4,85 \%$ & $80,08 \%$ \\
\hline 3055 & $(\mathrm{R} \$ 5197,50 / \mathrm{R} \$ 10.7982,25) \times 100 \%$ & $4,81 \%$ & $84,89 \%$ \\
\hline 1060 & $(\mathrm{R} \$ 3750,00 / \mathrm{R} \$ 10.7982,25) \times 100 \%$ & $3,47 \%$ & $88,36 \%$ \\
\hline 5050 & $(\mathrm{R} \$ 2652,00 / \mathrm{R} \$ 10.7982,25) \times 100 \%$ & $2,46 \%$ & $90,82 \%$ \\
\hline 1045 & $(\mathrm{R} \$ 2412,00 / \mathrm{R} \$ 10.7982,25) \times 100 \%$ & $2,23 \%$ & $93,05 \%$ \\
\hline 5070 & $(\mathrm{R} \$ 2346,00 / \mathrm{R} \$ 10.7982,25) \times 100 \%$ & $2,17 \%$ & $95,23 \%$ \\
\hline 3025 & $(\mathrm{R} \$ 2010,00 / \mathrm{R} \$ 10.7982,25) \times 100 \%$ & $1,86 \%$ & $97,09 \%$ \\
\hline 7080 & $(\mathrm{R} \$ 1988,00 / \mathrm{R} \$ 10.7982,25) \times 100 \%$ & $1,84 \%$ & $98,93 \%$ \\
\hline 1010 & $(\mathrm{R} \$ 1057,50 / \mathrm{R} \$ 10.7982,25) \times 100 \%$ & $0,98 \%$ & $99,91 \%$ \\
\hline 3010 & $(\mathrm{R} \$ 100,00 / \mathrm{R} \$ 10.7982,25) \times 100 \%$ & $0,09 \%$ & $100,00 \%$ \\
\hline
\end{tabular}

Fonte: Martins (2005, P.164)

Depois de todos os dados e porcentagens definidos faz-se a curva ABC.

Figura $n^{\circ} 1$ - Curva ABC

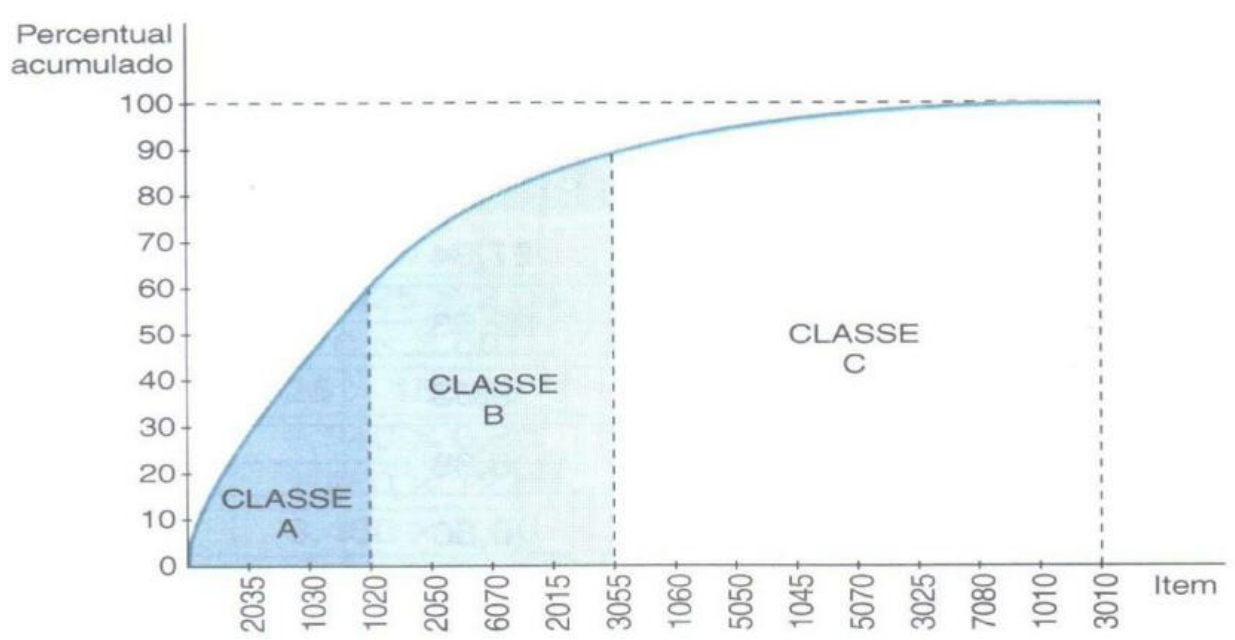

Fonte: Martins (2005, P.165)

De acordo com Martins (2001), na busca de tais objetivos, os administradores dispõem de vários indicadores, como o do giro dos estoques, da cobertura, da acurácia e da análise ABC tradicional. Além destes, a criticidade assume importância cada dia maior. Muitas vezes, a falta de um item de baixíssimo custo e pequena rotatividade pode parar toda uma fábrica, com prejuízos de milhares de reais.

Diante dos fatos descritos anteriormente percebe-se o quanto a administração de materiais ou a própria gestão são de suma importância para a empresa, pois, como foi citada 
por alguns autores, imobilização elevada de estoque é perda de lucros, e materiais em níveis a baixo de reposição é perigo de perda de clientes.

O papel fundamental da administração de materiais é saber manter o equilíbrio da demanda com o que se tem para oferecer ao cliente e sanar as necessidades do mesmo. E isso com auxilio de ferramentas de gestão e a tecnologia.

\section{MATERIAIS E MÉTODOS}

Conforme as palavras de Rover (2006, p. 100) "A especificação da metodologia do projeto é a que abrange maior número de itens, pois responde, a um só tempo, às questões: Como? Com quê? Onde fazer? Quanto? Quando?’. A seguir podemos evidenciar alguns itens interligados entre eles e que estão contidos dentro da metodologia.

\subsection{Classificação da pesquisa}

Segundo Prodanov e Freitas (2013, p. 24), “método cientifico é o conjunto de processos ou operações mentais que devemos empregar na investigação".

No que tange seu objetivo, a pesquisa em questão será descritiva mediante as afirmativas de Gil (2008, p. 42) que conceitua a pesquisa descritiva da seguinte forma: "as pesquisas descritivas têm como objetivo primordial a descrição das características de determinada população ou fenômeno ou, então, o estabelecimento de relações entre variáveis."

Quanto à abordagem do problema, a pesquisa será qualitativa referenciada por Prodanov e Freitas (2013, p. 24), os autores afirmam como a abordagem qualitativa como "o ambiente de natural é fonte direta para coleta de dados, interpretação de fenômenos e atribuição de significados".

Quanto à natureza esta pesquisa classifica-se como um estudo de caso, pois conforme Barros e Lehfeld (2007, p. 112) “a origem do termo 'estudo de caso' remonta à pesquisa psicológica, referindo-se à análise minuciosa de um caso individual, explicativa de patologias".

Todavia, Yin (2003) contextualiza que estudo de caso é "uma investigação empírica que estuda um fenômeno contemporâneo dentro de seu contexto real especialmente quando os limites entre o fenômeno e o contexto não são claramente evidentes". 
Gil (2008) diz que consiste no estudo profundo e exaustivo de um ou poucos objetos, de maneira que permita seu amplo e detalhado conhecimento, tarefa praticamente impossível mediante outras metodologias, sendo esta uma modalidade de pesquisa utilizada nas ciências sociais e biomédicas, o mesmo autor explicita que essa modalidade pode ser dividida em várias etapas como: formulação do problema, definição da unidade-caso, determinação do número de casos, elaboração do protocolo, coleta de dados, avaliação e análise dos dados e preparação do relatório.

\subsection{Processo de pesquisa e especificação dos dados}

A pesquisa foi preparada em duas etapas, primeiramente com a etapa de elaboração da base teórica através da confecção do escopo do artigo, seguida da segunda etapa que se trata dos levantamentos de dados para obtenção de informações referente aos resultados esperados sobre o assunto proposto.

Por trata-se de uma pesquisa que gera uma base de dados e informações, a utilização de ferramentas foi escolhida com intuito de satisfazer de forma mais produtiva a necessidade real de coleta das informações necessárias.

\subsection{Instrumentos de coletas de dados e amostragem}

A coleta de dados ocorreu em uma Instituição de Ensino Superior situada em Porto Velho-RO. As informações foram coletadas através de um software TOVT’S, juntamente com a equipe que compõe o setor responsável pelo fluxo de materiais adquiridos e distribuídos na Instituição de Ensino Superior.

Algumas ferramentas como o Excel foi utilizado como suporte para elaboração de planilhas e filtros de resultados para determinar a curva ABC.

\section{ANALISE E DISCUSSÃO DOS RESULTADOS}

\subsection{Descrever a funcionalidade do setor responsável pelo controle de estoque e administração de materiais.}

O setor responsável pelo fluxo de materiais da Instituição se chama, setor de patrimônio, o mesmo é composto por uma equipe de 04 pessoas. 
Tratando-se da funcionalidade para aquisição e distribuição de materiais, o setor atende em média 20 setores, todos com suas atividades diferentes. O patrimônio no período de 30 dias tem como finalidade atender a necessidades desses setores conforme o planejamento anual que é definido juntamente com a diretoria da IES.

O setor responsável realiza um controle de estoque manual e com o sistema, chamado TOVT'S o mesmo tem como finalidade controlar entradas e saídas de mercadorias, dando o demonstrativo dos gastos positivos e negativos que foram realizados pela Instituição juntamente com o fluxo de cada setor que compõem a IES.

Para realizar a compra de um material, a solicitação primeiramente tem que ser feita por um documento que é chamado CI (Controle Interno), onde é feita a análise do pedido e em seguida o colaborador que fez a retirada do material assina um formulário que contém as informações que devem ser preenchidas como: Quantidade, nome do material, setor responsável e assinatura.

Esse é o primeiro momento em que inicia o controle de saída de materiais do setor, todos os dias essa lista é impressa com a data e o dia da semana, pois através dela são repassadas as informações para o sistema TOVT'S em seguida o mesmo da um breve resumo do dia da semana em que houve mais retirada de materiais e qual tipo de material. Esse é uma das principais movimentações do dia a dia do setor, em casos de solicitações com quantidades maiores, materiais que não estejam estocados no setor, há um processo a ser feito para realizar a aquisição do material e entrega para o setor solicitante, nesses casos específicos de materiais não estocado e menos rotativo, é feito uma CI (Controle Interno) novamente, porém a mesma é encaminhada para a diretoria solicitando a liberação da compra do material, em seguida a equipe realiza a cotação, o setor obtém uma parceria de fornecedores que auxiliam e facilitam na hora da compra do material.

Outros processos são realizados com frequência dentro do setor, além do controle inicial simples, diariamente essas informações são registradas no sistema, há uma contagem semanal de conferencia de estoque, os produtos priorizados são os produtos mais rotativos, no caso produtos de reposição, como papel higiênico, produtos de limpezas e entre outros.

Alguns produtos de expedientes são comprados semestralmente, como: canetas, papel, corretivos e tesouras. O setor de patrimônio tem um trabalho com setor de manutenção mais especifico, pois o mesmo trabalha com obras, ajustes em setores, limpezas e ocorrências imprevisíveis, é o setor que tem seus produtos comprados fora a parte desta lista que é feita mensalmente, os produtos utilizados pelo setor são comprados com o dinheiro do fundo fixo, é um valor fixo do setor de patrimônio, que tem como finalidade atender as necessidades que 
não estão inclusas no planejamento e sim para um momento específico e alguns produtos da manutenção são comprados eventualmente, por exemplo; pregos, parafusos, fios e entre outros.

Em questão de contagens e conferencias, a uma conferencia semanal para a equipe ter um breve controle das saídas de materiais e as suas necessidades de reposição, a um levantamento também realizado juntamente com a equipe da manutenção todo mês no dia 20 , onde a finalidade é fazer a contagem dos materiais e os produtos que estão em falta, por fim a uma contagem mensal que é feita no primeiro dia útil do mês, onde o setor faz a contabilidade de todas as mercadorias e serviços realizados para comparar com o que tem no sistema e com o que tem no físico.

Tratando-se de notas fiscais, dinheiro, recibos entre outros documentos que precisam de uma atenção maior, é confiado a quatro colaboradores, supervisor, assistente administrativo que é responsável pela cotação e compra de materiais e a analista contábil que tem como uma das suas funções fazer a conferência das notas fiscais, lançamentos para o sistema e o encaminhamento para o setor contábil da Instituição.

Apesar de o setor ser composto por poucas pessoas, é perceptível que o mesmo realiza um processo adequado para o funcionamento do fluxo de aquisição e distribuição de materiais.

\subsection{Identificar os materiais mais rotativos dentro do estoque da instituição.}

Os dados coletados com o setor de patrimônio via sistema teve os resultados esperados que pudessem contribuir para o desenvolvimento necessário da pesquisa. De modo geral todos os setores atingem uma rotatividade significante no estoque da instituição, porém dois deles foram os que mais chamaram atenção, por ter mais rotatividade, diversidade de materiais e situações que contribui para a melhor interpretação do leitor e da Instituição em relação ao fluxo e administração de materiais dentro da IES.

\subsubsection{Material de expediente}

Material de expediente, a rotatividade desse seguimento é definida através da identificação do seguimento da empresa, o perfil dos setores que utilizam os materiais, o grau de necessidade que cada um dos itens influencia dentro dos setores. Identificando esses itens é possível analisar o grau de rotatividades dos materiais e suas devidas importâncias. 
Figura 2 - Material de Expediente

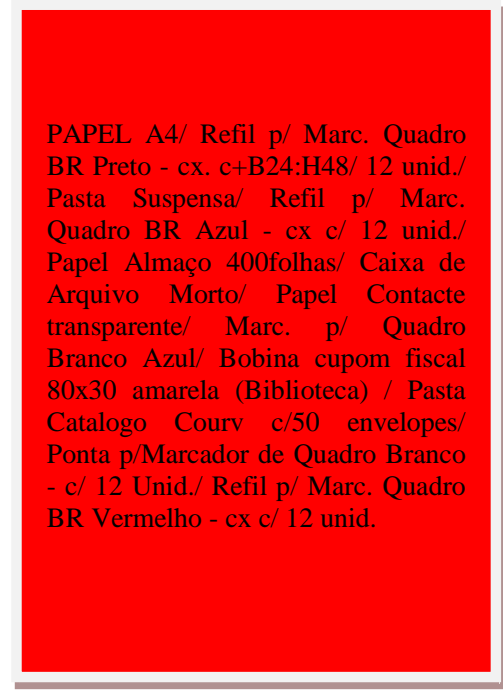

Bobina cupom fiscal 57x22 amarela/ Perfurador Grande/ Marc. p/ Quadro Branco Vermelho/ Pasta A-Z / Saco Perfurado - Pacote 100 Unid./ Grampeador pequeno/ Pincel Marcador QD BC PT/ Calculadora Pequena/ Caneta Azul/ Anote e cole/ Fita adesiva / Grampo p/ Grampeador 26/6/ Pilha AAA - C/ 2 Unid. Caixa de Arquivo Morto simples / Marca Texto/ Colchete 6/72/ Visor para pasta suspensa - Pacote c/ 50 unid./ PILHA AA C/ 2/ Romeu e Julieta Paconte c/ 50 Unid./ Romeu e Julieta - Paconte cl 50 Unid./ Livro de Protocolo 104 Folhas.

Fonte: Dados da pesquisa (2018)

No quadro vermelho é possível detectar os produtos mais rotativos, esses são os produtos que recebem a contagem semanalmente, que necessitam de uma reposição dentro de um prazo menor que os demais. Esses materiais têm como finalidade atender todos os setores administrativos, o setor de pessoal e tesouraria no quesito de bobinas e caixas para arquivos, o material refil para pincel para utilizar em quadros brancos tem como finalidade atender o setor acadêmico, salas de aula e entre outros materiais que supre a necessidade de cada setor.

No quadro amarelo pode-se observar que se refere aos materiais com pouca rotatividade, onde os mesmos recebem contagem semestralmente. Um dos fatores que influenciam na contagem semestral é pelo fato da Instituição solicitar ao setor responsável a fazer uma estocagem em grande escala para aguentar o período de 06 meses.

No quadro verde estão destacados os materiais que possuem uma rotatividade anual, pode-se dizer que são materiais em que são pedidos poucas vezes pelos setores, tendo a sua compra reduzida, são materiais que tem a duração maior e alguns dos materiais como papeis especiais são solicitados somente para alguns eventos em que algum determinado setor solicita, por exemplo, o marketing.

\subsubsection{Material de Manutenção}

Material de manutenção, esse seguimento pode ser observado desde o processo de compreender o setor responsável pelo fluxo de materiais da Instituição que obtêm um acompanhamento diferenciado dos demais. Importante ressaltar que o setor de manutenção engloba limpeza, copa, cozinha, parte elétrica, hidráulica e entre outros serviços como 
acompanhamentos de obras, por isso ele define o maior fluxo de materiais da IES, ultrapassando o material de expediente. Nesse caso, iremos apresentar somente o fluxo de materiais da parte hidráulica e elétrica.

No quadro vermelho, estão destacados os itens de mais rotatividade, eles se destacam pelo fato de serem produtos que são trocados, tem reposição com mais frequência, um dos fatores que influenciam a maior rotatividade, por exemplo, das lâmpadas, são os períodos em que ocorrem chuvas, onde a queda de energia é maior, apesar de a Instituição ter o gerador, infelizmente acaba causando danos nas lâmpadas da IES.

No quadro amarelo, pode-se observar que os itens em destaque são aqueles que atendem as necessidades das ocorrências em imediato, porém a durabilidade de ocorrer novamente é de um prazo menor, por isso não a tanta rotatividade, por exemplos, ocorridos com as centrais de ar acontecem com alguns setores, salas de aula, porém em um quantitativo menor. Alguns desses itens são comprados conforme exposto anteriormente no processo do setor responsável, são itens comprados somente uma vez e não há tanta necessidade de ter em grande quantidade no estoque.

No item verde, verifica-se que os itens em destaque são os produtos com a rotatividade quase inexistentes, a contagem desses produtos depende dos projetos que a empresa realiza durante o ano, são produtos que fazem parte do estoque, mas não há uma rotatividade suficiente do mesmo. Por exemplo, esses produtos são adquiridos no período em que a empresa está realizando uma obra, um evento para o setor de marketing ou reformas no prédio.

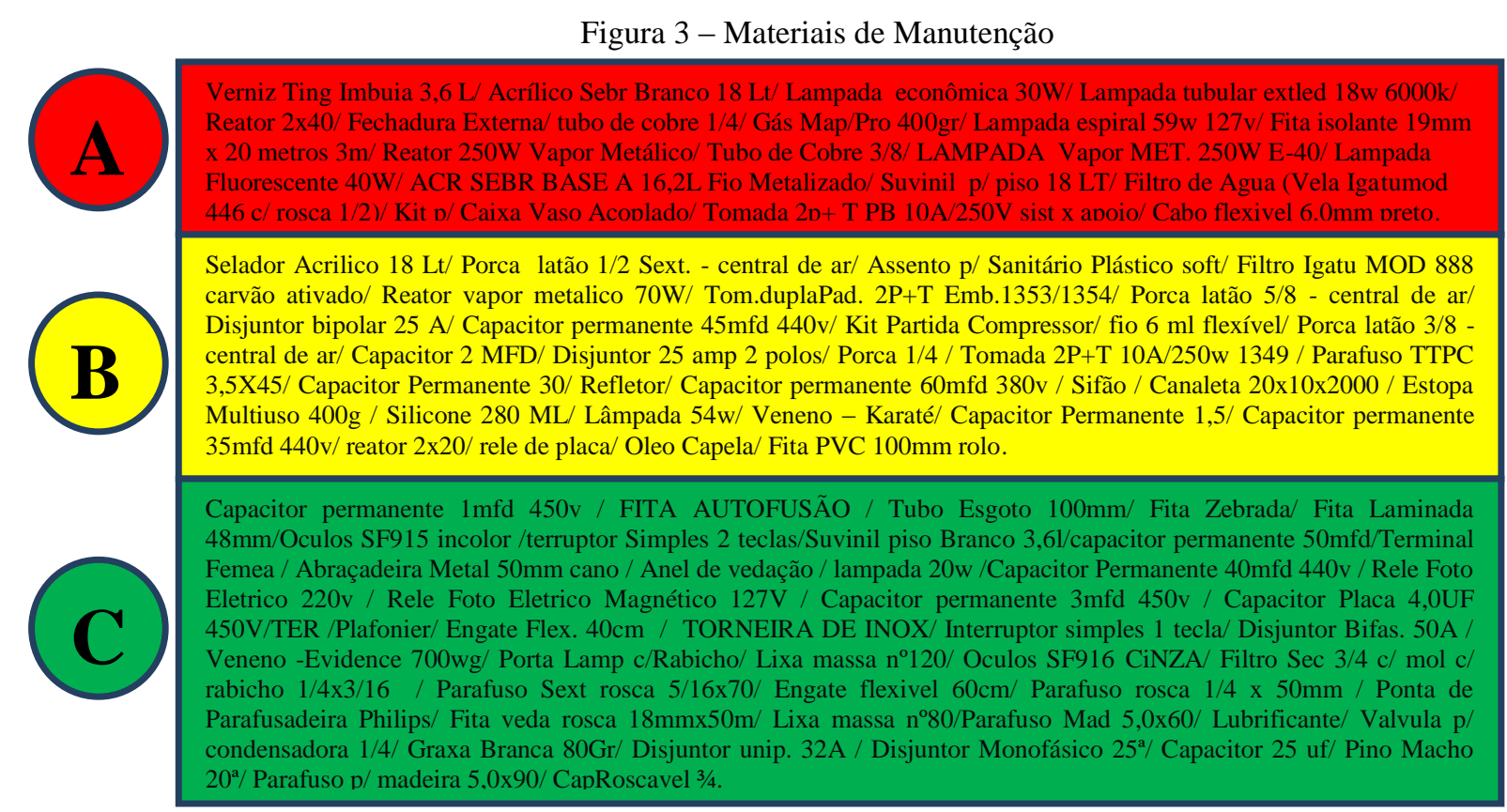

Fonte: Dados da pesquisa, 2018. 


\subsection{Aplicar possiveis ferramentas para realização da curva ABC.}

Realizado a coleta das devidas informações dos produtos mais rotativos, definidos os seguimentos e setores que serão analisados, teremos base para realizar a curva $A B C$. Uma das ferramentas que auxiliaram na elaboração da curva $\mathrm{ABC}$ além do sistema, foi à planilha de Excel, onde foram colocadas as devidas informações para que as mesmas pudessem ser geradas em gráficos para assim demonstrar os resultados dos produtos mais rotativos de forma aprimorada e esclarecedora.

O gráfico 1 demonstra a curva $\mathrm{ABC}$ dos materiais de expediente, pode-se perceber que a maior movimentação desses itens está na categoria $\mathrm{A}$, como descrito anteriormente, são itens que possuem mais rotatividade e uso imediato no dia a dia da empresa. Posto isto, através do gráfico é possível que se tenha a compreensão dos itens que acabam tornando-se prioridades nos quesitos, reposição, estocagem, aquisição e outras analises que auxiliam nas tomadas de decisões da empresa, contribuindo para uma prevenção de imobilização de capital e gerando giros de estoques equilibrado com a necessidade da demanda da instituição.

Gráfico 1 - Curva ABC dos materiais de expediente

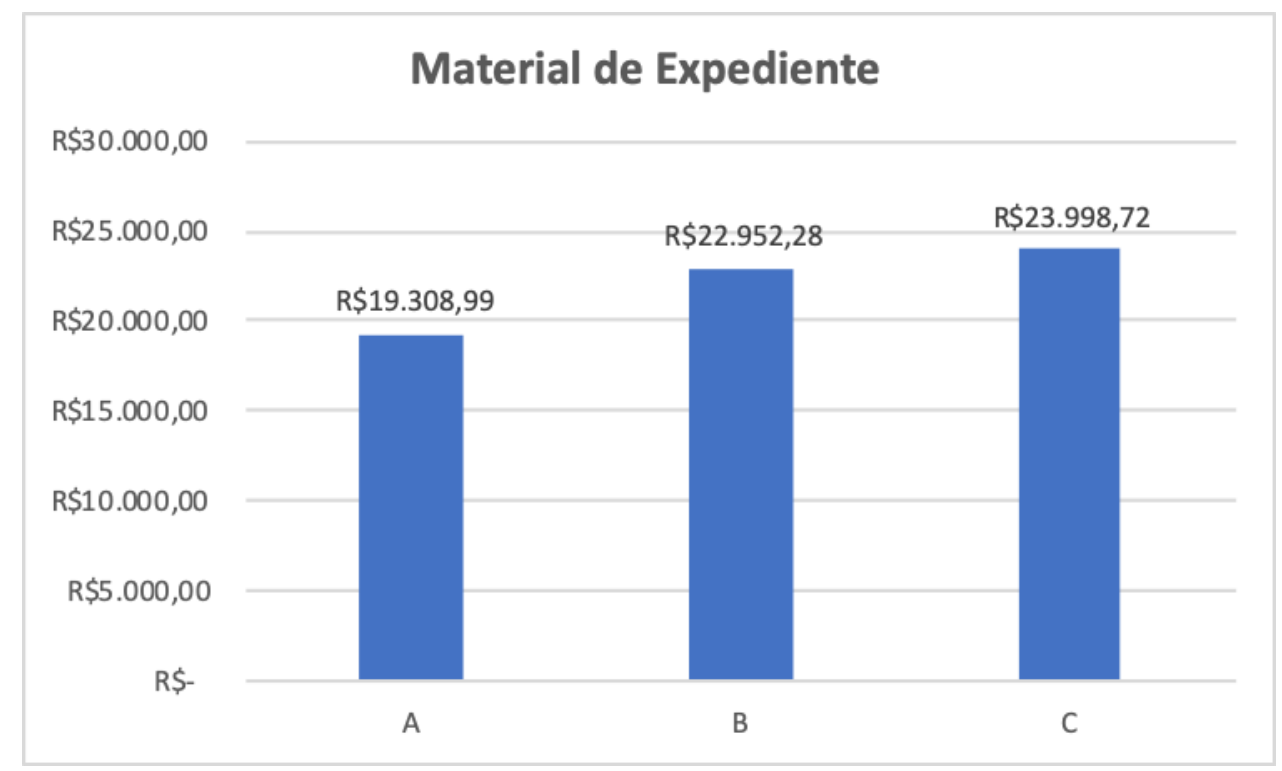

Fonte: Dados da Pesquisa

O gráfico 02 demonstra a curva $\mathrm{ABC}$ dos materiais de manutenção, o setor que tem o maior fluxo de materiais da instituição pelo fato de englobar várias responsabilidades e equipes como serviços gerais, manutenção, parte elétrica, hidráulica e obras. Através do gráfico é perceptível que os itens que geraram os valores da classe A superam os valores das 
demais classes, como demonstrado na figura 2 os itens que compõe essa classe são os que mais possuem rotatividade no dia a dia da empresa, atendendo diretamente os setores administrativos e a parte educacional, os demais itens são aqueles em que são adquiridos dependendo dos eventos e projetos que a instituição vem a executar.

Gráfico 2 - Curva ABC dos materiais de Manutenção

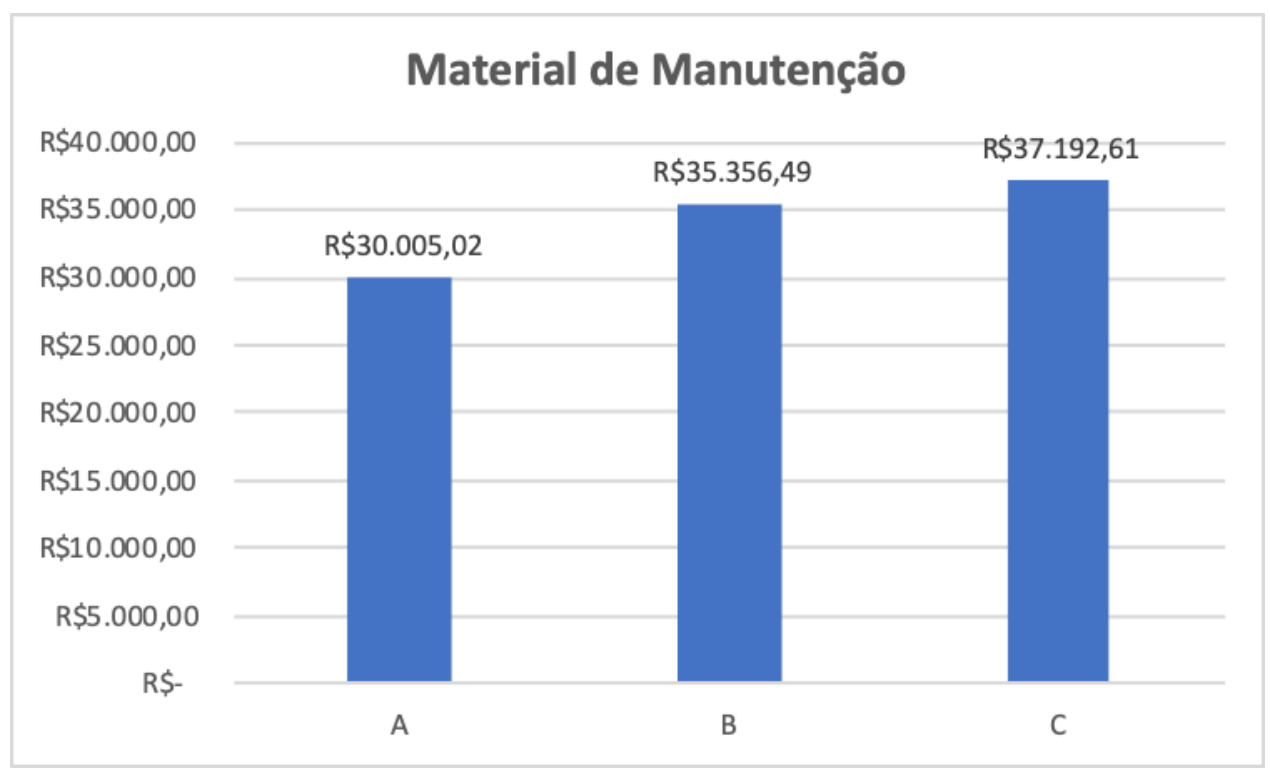

Fonte: Dados da Pesquisa

\subsection{Descrever a importância da curva abc na administração de materiais dentro da instituição de ensino superior.}

Doravante Martins (2005, p. 162) afirma que a análise ABC é uma das formas mais usuais de se examinar estoques. Essa análise consiste na verificação, em certo espaço de tempo (normalmente 06 meses ou 1 ano), do consumo, em valor monetário ou quantidade, dos itens de estoque, para que eles possam ser classificados em ordem decrescente de importância. Aos itens mais importantes de todos, segundo a ótica do valor ou da quantidade, dá-se a denominação itens classe A, aos intermediários classe B e aos menos importantes itens classe C.

Compreende-se que o setor de patrimônio obtêm um controle básico de contagem de materiais, aquisição e distribuição de mercadorias, porém pode-se afirmar que o mesmo diante da aplicação da ferramenta obteve uma visão holística sobre a rotatividade dos seus produtos, teve a percepção sobre as prioridades dos mesmos em relação aos seguimentos de materiais de expediente e manutenção. 
Além da visão holística obtida em relação a rotatividade e priorização dos produtos, pode ser observado a quantidade de materiais imobilizados dentro do estoque, nesse caso algumas situações colaboraram para a existência desse ocorrido, como citado acima em períodos de chuva, o setor tem a necessidade de estocar lâmpadas por conta das quedas de energia que acabam causando danos na IES, um dos fatores que contribuíram para o alto valor de capital imobilizado, as precipitações nas tomadas de decisões em relação a aquisição de mercadorias de expediente acabaram gerando giros de estoques menores e por fim deixando o acumulo de materiais em estoque resultando no aumento de capital imobilizado.

Diante de alguns fatos expostos, verifica-se que a ferramenta de curva $\mathrm{ABC}$ tem como finalidade contribuir para o supervisor e empresa obter uma visão holística em relação ao seus investimentos e gastos.

Através das informações coletadas e as analises dos seguimentos como, material de manutenção e material de expediente, pode-se enfatizar que a curva $\mathrm{ABC}$ na administração do setor responsável pelo fluxo desses materiais pode contribuir para grandes tomadas de decisões e aproveitamento para alinhar e iniciar novos métodos de processos a serem aplicados dentro do setor, como consequência trará bons resultados para a Instituição de Ensino, evitando investimentos que fiquem imobilizados, identificando a rotatividade dos mesmos e buscando um equilíbrio em relação à distribuição e aquisição das mercadorias para atender as necessidades dos setores e da empresa.

\section{CONSIDERAÇÕES FINAIS}

Para compreender o setor responsável pela administração, aquisição e distribuição de materiais da Instituição, foi necessário compreender o seu processo e suas estratégias para desenvolver as atividades necessárias para o funcionamento da IES.

A administração de materiais vai além do controle de estoque, há vários campos além de materiais e financeiros que precisam ser bem administrados para haver redução de custos e desperdício. Por conseguinte, com as informações coletadas e aplicação da curva $\mathrm{ABC}$, foi identificado que o setor de patrimônio, responsável por essa administração realiza um controle simples em relação ao fluxo de mercadoria, no caso somente a conferencia com o sistema e o físico, o processo do departamento não há tanta complexidade, porém os resultados do processo de controle são satisfatório (BENFICA,2013).

Com a aplicação da curva ABC ficou esclarecido alguns itens como a imobilização de capital e a quantidade de giros de estoques insuficientes dentro da empresa, à identificação de 
mercadorias mais rotativas contribuíram para uma visão melhorada sobre a necessidade dos setores.

Conforme Pozo (2016) os ocorridos em relação a imobilização de capital já aconteciam no fim do século passado, ou seja, foi identificado que $80 \%$ das mercadorias encontravam-se concentrada com a população, não tendo rotatividade, significando capital imobilizado. Sendo assim, Martins (2005) afirma que a função da administração de materiais é reter a menor quantia de capital em estoque.

Exposto essas afirmações compreende-se que o setor responsável pela administração de materiais tem grandes responsabilidades dentro da instituição de ensino, contribuindo com as principais decisões da empresa que como consequência poderá levar a empresa a resultados positivos ou negativos, desta forma o setor de patrimônio da instituição tem um papel verdadeiramente estratégico dentro da empresa.

Compreendendo o processo do departamento, identificamos as principais mercadorias mais rotativas dentro da instituição, as suas necessidades para com os setores e sua importância no dia a dia para a funcionalidade da IES, analises feitas somente com dois seguimentos que foram materiais de expediente e materiais de manutenção, os mesmos foram escolhidos por obter uma rotatividade maior dentro da IES. Muito desses materiais entram em suas classificações na curva $\mathrm{ABC}$ pelos seguintes fatores, nas classes $\mathrm{A}$, do qual são os materiais mais rotativos e prioritários para a funcionalidade da IES, compreende-se que são materiais que soluciona as problemáticas diárias e faz com que a instituição funcione com qualidade, dentro da classe B encontra-se aqueles materiais que são intermediários, são solicitados em períodos mais curtos, tem uma durabilidade maior e não há necessidade de reposições mensais ou até mesmo semanais, dentro da classe $\mathrm{C}$ encontram-se os materiais que são utilizados eventualmente, ou seja, quando a empresa desenvolve algum evento, realiza obras ou reformas, são produtos que não estão estocados e caso sejam o período de estocagem é limitado.

Nesse enfoque, Martins (2005) afirma que a análise ABC é uma das formas mais usuais de se examinar estoques, sendo assim podemos compreender que a ferramenta de curva $\mathrm{ABC}$ auxilia a empresa em todos os levantamentos de informações, esclarecimentos e comparações.

Tendo como objetivo levar a empresa a uma visão melhorada dos seus investimentos e gastos, contribuindo para as tomadas de decisões, novas estratégias que permitem com que a empresa encontre o ponto de equilíbrio para atender a necessidade dos setores administrativos e acadêmicos. 


\section{REFERÊNCIAS}

ALBUQUERQUE, André. Administração de Materiais: Noções e ferramentas. Disponível em: 〈http://www.portal-administracao.com/2013/12/administracao-de-materiais-

conceito.html> Acesso em: 03/05/2018.

BALLOU, R. H. Logística Empresarial. São Paulo: GEN, 2013.

BARROS, A.J.S; LEHFELD,N.A. S Fundamentos da Metodologia Cientifica. São Paulo: Prentice Hall, 2007.

BASTOS, Marcelo. Administração da Produção e Operações. Disponível em: <http://www.portal-administracao.com/2013/11/administracao-da-producao-conceitos.html > Acesso em: 03/05/2018.

CHIAVENATO, Idalberto. Planejamento e Controle da Produção. 2.ed. Barueri, SP: Manole, 2008.

CHIAVENATO, Idalberto. Gestão da Produção: UMA ABORDAGEM

INTRODUTÓRIA. 3.ed. Barueri, SP: Manole, 2014.

DUMAS, Ana Carolina. Administração de Materiais: Um planejamento Indispensável. Disponível em:

$<$ http://faef.revista.inf.br/imagens_arquivos/arquivos_destaque/EyDVEFmpQMWdGLQ_201 3-5-3-12-4-41.pdf > Acesso: 29/05/2018.

FREITAS, Ernani Cesar. Metodologia - Estudo e Ensino I. Novo Hamburgo: Feevale, 2013. GIL, Antônio Carlos. Como elaborar projetos de pesquisa. 4. ed. São Paulo: Atlas, 2008.

GONSALEZ, Wagner. A administração da produção. Disponível em:

$<$ http://www.administradores.com.br/artigos/carreira/a-administracao-da-producao/23401/> Acesso em: 03/05/2018.

MARTINS, Martins Garcia. Administração de Materiais e Recursos Patrimoniais. /Martins Garcia Martins/1a edição. São Paulo: Saraiva, 2005

MARTINS \& LAUGENI. Administração da Produção. 1. ed. São Paulo: Saraiva, 2006.

PRODANOV, Cleber Cristiano; FREITAS, Ernani Cesar de. Metodologia do trabalho científico: métodos e técnicas da pesquisa e do trabalho acadêmico. 2. ed. Novo Hamburgo: Feevale, 2013. 277p.

POZO, Hamilton. Administração de Recursos Materiais e Patrimoniais. 3. ed. São Paulo: Editora Atlas, 2016. 92 p.

VIANA, João José. Administração de Materiais. Ed, São Paulo: Editora Atlas, 2010. 64 p. 
SOUZA, Alexandre. Principais ferramentas de gestão empresarial para a busca da qualidade. Disponível em:

$<$ http://www.administradores.com.br/artigos/marketing/principais-ferramentas-de-gestaoempresarial-para-a-busca-da-qualidade/21112/ > Acesso em: 03/05/2018.

SLACK, Nigel; BRANDON-JONES, Alistair; JOHNSTON, Robert. Administração da produção. São Paulo: Atlas, 2000. $1^{\text {a }}$ Edição.

SLACK, Nigel; BRANDON-JONES, Alistair; JOHNSTON, Robert. Administração da

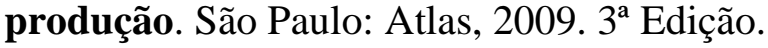

SLACK, Nigel; BRANDON-JONES, Alistair; JOHNSTON, Robert. Administração da produção. São Paulo: Atlas, 2018. $8^{\circ}$ Edição 